\title{
The Phenomenology of Depersonalization
}

\section{Background/Aims}

Depersonalization is a condition characterized by changes in individual auto-experience and comes with feelings of unreality or detachment towards its mental processes, body or environment;

- It happens in healthy individuals or related to medical non-psychiatric and psychiatric disorders and related to effect of substance use; - Additionally it may happen as an autonomous presentation resulting in depersonalization and derealization disorder;

- It is often undervalued but results in an important phenomenological presentation and has a significative impact on the individual.

\section{Objectives}

With this work the authors want to review depersonalization and its symptoms in order to shed more comprehension about this entity.

\section{Materials and methods}

The authors reviewed, non systematically, the literature, through search in textbooks and papers related to this topic in the databases of Pubmed and Sciencedirect selecting the relevant scientific papers addressing this theme.

\section{Results}

$>$ Depersonalization is a rich and interesting phenomelogical manifestation;

$>$ Changes in auto-consciousness of the individual characterized by feelings of irreality or distance to its mental processes, body or external context;

$>$ Usually perceived as an anomalous experience and causes anxiety, angst and disconfort;

$>$ Some authors grouped these anomalous experiences in multiple clusters:

\section{Anomalous Body Experiences}

- Changes in bodily belonging sensation - loss of feeling of belonging of self to its own body (partial/total);

- Sensation of loss of "agency" - loss of feeling of belonging of own actions to the individual;

- "Disembodiment" - personal experience felt as outside the physical boundaries of body;

- Somatosensorial distortions - non-specific, bodily perceptual experience changes (weight, size of body, others);

- Increase of sense of self-observation - feeling as observers of themselves during normal activity.

\section{Emotional Numbness}

- Loss or change in the capacity of feeling emotions in a natural and normal way feeling them as decreased.

\section{Anomalies of subjetive memories}

- Changes in the capacity of remembering past events or producing mental images - able to evoke factual component of the event but don't have the usual sensations related to those memories that give it the personal mark.

They may present in the individual in a way that he feels like an external observer of the memory. May consist in three presentations:

- Changes in intensity of the memory - memories less detailed, less colorful, less vivid and sometimes even absent;

- Changes in experiences of time - changes in the way events are timely situated, difficulties in feeling time and even feeling outside of time;

- Sensation of an empty mind - feeling their mind empty, like its memories are absent.

\section{Detachment from external environment (Derealization)}

- Feeling detached from the external environment and feeling it as unreal. Usually occurs together with depersonalization.

\section{Conclusions}

- Depersonalization is a phenomenon caracterized by a change in personal experience of the individual;

- Due to its inespecificity often is devalued by clinicians and happens in pathological or non-pathological contexts or independently as a disorder;

- Depersonalization by its multiple symptoms is a very rich psychopatologic entity but with neuropsychobiological basis yet not fully. 